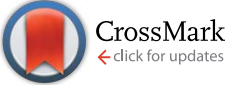

Cite this: RSC Adv., 2014, 4, 36771

\title{
Extensive counter-ion interactions seen at the surface of subtilisin in an aqueous medium $\dagger$
}

\author{
Michele Cianci, ${ }^{\star a}$ Jacopo Negroni, ${ }^{a}$ John R. Helliwell ${ }^{b}$ and Peter J. Halling ${ }^{c}$
}

Received 30th June 2014

Accepted 17th July 2014

DOI: $10.1039 / c 4 r a 06448 h$

www.rsc.org/advances

The extent of protein and counter-ion interactions in solution is still far from being fully described and understood. In low dielectric media there is documented evidence that counter-ions do bind and affect enzymatic activity. However, published crystal structures of macromolecules of biological interest in aqueous solution often do not report the presence of any counter-ions on the surface. The extent of counter-ion interactions within subtilisin in an aqueous medium has been investigated crystallographically using $\mathrm{CsCl}$ soak and X-ray wavelength optimised anomalous diffraction at the Cs K-edge. Ten $\mathrm{Cs}^{+}$, as well as six $\mathrm{Cl}^{-}$sites, have been clearly identified, revealing that in aqueous salt solutions ions can bind at defined points around the protein surface. The counter-ions do not generally interact with formal charges on the protein; formally neutral oxygens, mostly backbone carbonyls, mostly coordinate the $\mathrm{Cs}^{+}$ions. The $\mathrm{Cl}^{-}$ion sites are also found likely to be near positive charges on the protein surface. The presence of counter-ions substantially changes the protein surface electrical charge. The surface charge distribution on a protein is commonly discussed in relation to enzyme function. The correct identification of counter-ions associated with a protein surface is necessary for a proper understanding of an enzyme's function.

\section{Introduction}

Ions can interact at many places on a protein molecule. The mechanism of interaction between ions and a protein is far from being fully understood. It is also a matter of debate whether the nature of such interactions is site-specific, or nonspecific i.e. depending on interaction with nearby groups. ${ }^{\mathbf{1 , 2}}$

${ }^{a}$ European Molecular Biology Laboratory c/o DESY, 22603 Hamburg, Germany. E-mail: m.cianci@embl-hamburg.de; Fax: +49 40 89902149; Tel: +49 4089902118

${ }^{b}$ School of Chemistry, University of Manchester, Oxford road, Manchester, M13 9PL, UK. E-mail: j.r.helliwell@man.ac.uk

'WestCHEM, Department of $P \&$ A Chemistry, University of Strathclyde, Glasgow G1 1XL, UK. E-mail: p.j.halling@strath.ac.uk; Fax: +44 (0)141 548 4822; Tel: +44 (0) 1415482683

$\dagger$ Electronic supplementary information (ESI) available. See DOI: $10.1039 / \mathrm{c} 4 \mathrm{ra} 06448 \mathrm{~h}$
Some interactions take place at relatively strong and specific binding sites, and have been well studied. ${ }^{3}$ At higher salt concentrations, more ions become associated, with important and significant effects on function associated with Hofmeister effects. ${ }^{4-6}$ Properties following the Hofmeister series include enzyme activity, protein stability, protein-protein interactions, protein crystallization, optical rotation of sugars and amino acids and bacterial growth, as reviewed by Zhang and Cremer. ${ }^{7}$ Further elucidation of the sites of ion interactions on protein surfaces is warranted so as to better rationalize ion-specific, Hofmeister, effects.

Molecular dynamics simulations have been used to elucidate the affinity of cations like $\mathrm{K}^{+}$and $\mathrm{Na}^{+}$on protein surfaces in aqueous solutions. These cations show a strong preference for aspartic and glutamic acid side chains, with minor contributions from other side chains or from carbonyl oxygens. ${ }^{8}$

The "law of matching water affinity" suggests that $\mathrm{K}^{+}$, a chaotrope, clusters water molecules only weakly, and, as such, it is mismatched in its water affinity to the strongly hydrated phosphates and carboxylates. $\mathrm{A} \mathrm{K}^{+}$ion would form weak, labile interactions with phosphate and carboxylate. ${ }^{\mathbf{1 0}}$

Molecular dynamics simulations have also shown that large soft anions such as $\mathrm{SCN}^{-}$and $\mathrm{I}^{-}$interact with the backbone of a folded protein via a hybrid binding site that consists of the amide nitrogen and an alpha-carbon, with $\mathrm{Cl}^{-}$ion binding far more weakly to the site. ${ }^{\mathbf{1 1}}$

Protein X-ray crystallography represents a source of information on these interactions with ions. If their identification is specifically targeted, confidence in ion assignments can be improved. The most common cations used in crystallisation, $\mathrm{Na}^{+}$and $\mathrm{NH}_{4}{ }^{+}$, are iso-electronic with water and hence will usually be falsely modelled in a protein X-ray crystal structure as waters, unless distinctive features of their coordination environment are clearly seen. Replacing these common counterions with ones based on heavier elements, but as similar as possible in their size and their chemistry, combined with anomalous diffraction measurements with softer X-rays ${ }^{12,13}$ can be used to unambiguously identify their binding sites. ${ }^{\mathbf{1 4 , 1 5}} \mathrm{We}$ 
have been exploring such methods to give definitive information about such counter-ion interactions when investigating proteins that had been transferred to a predominantly nonaqueous environment (acetonitrile) and where interactions with counter-ions might be expected to become stronger. The enzyme subtilisin Carlsberg, in acetonitrile, was shown to have no fewer than eleven defined binding sites for $\mathrm{Cs}^{+}$cations and eight for $\mathrm{Cl}^{-}$anions, with clear evidence from an enzyme assay that their binding affected function. ${ }^{\mathbf{1 4}}$

We report here that the same enzyme, shown to retain activity in $3.5 \mathrm{M}$ aqueous $\mathrm{NaCl},{ }^{16}$ has a substantial number of clear binding sites for these counter-ions. Using the same approach of $\mathrm{CsCl}$ soak and optimised anomalous diffraction measurements with softer X-rays, ten $\mathrm{Cs}^{+}$and six $\mathrm{Cl}^{-}$sites are unambiguously identified. This finding is rather unexpected, because the improved solvation of ions in water might be expected to reduce their binding to the protein in comparison with their behaviour in non-aqueous media. The electrical potential surface of the protein will be substantially affected by the presence of these counter-ions.

\section{Experimental section}

\section{Crystallization, cryo-protection and Cs soaking of crystals}

Subtilisin Carlsberg was purchased from Sigma (product code: P5380) and used for crystallization without further purification. The protein powder was dissolved in $330 \mathrm{mM}$ Na cacodylate buffer at $\mathrm{pH} 5.6$ to a concentration of $10 \mathrm{mg} \mathrm{mL}^{-1}$ and crystallized by the batch method from a buffer solution saturated with $\mathrm{Na}_{2} \mathrm{SO}_{4} \sim 13 \%$ (w/v) as precipitant. ${ }^{14}$ Needle morphology crystals grew over a period of two weeks to typical dimensions $50 \times 50 \times 400 \mu^{3}$. These 'native' crystals were cryo-protected using a solution of $25 \%$ glycerol and $75 \%$ buffer reservoir. The caesium derivative was prepared by soaking a single crystal with the above cryoprotectant containing $2 \mathrm{M} \mathrm{CsCl}$ for 1 minute.

\section{X-ray diffraction data collection and processing and subsequent protein structure refinement}

Data collection was performed on SRS BL100 ${ }^{17}$ Daresbury Laboratory. Diffraction data were collected using softer X-rays ${ }^{13}$

Table 1 Data collection, data processing and refinement statistics for aqueous subtilisin, with and without Cs soak

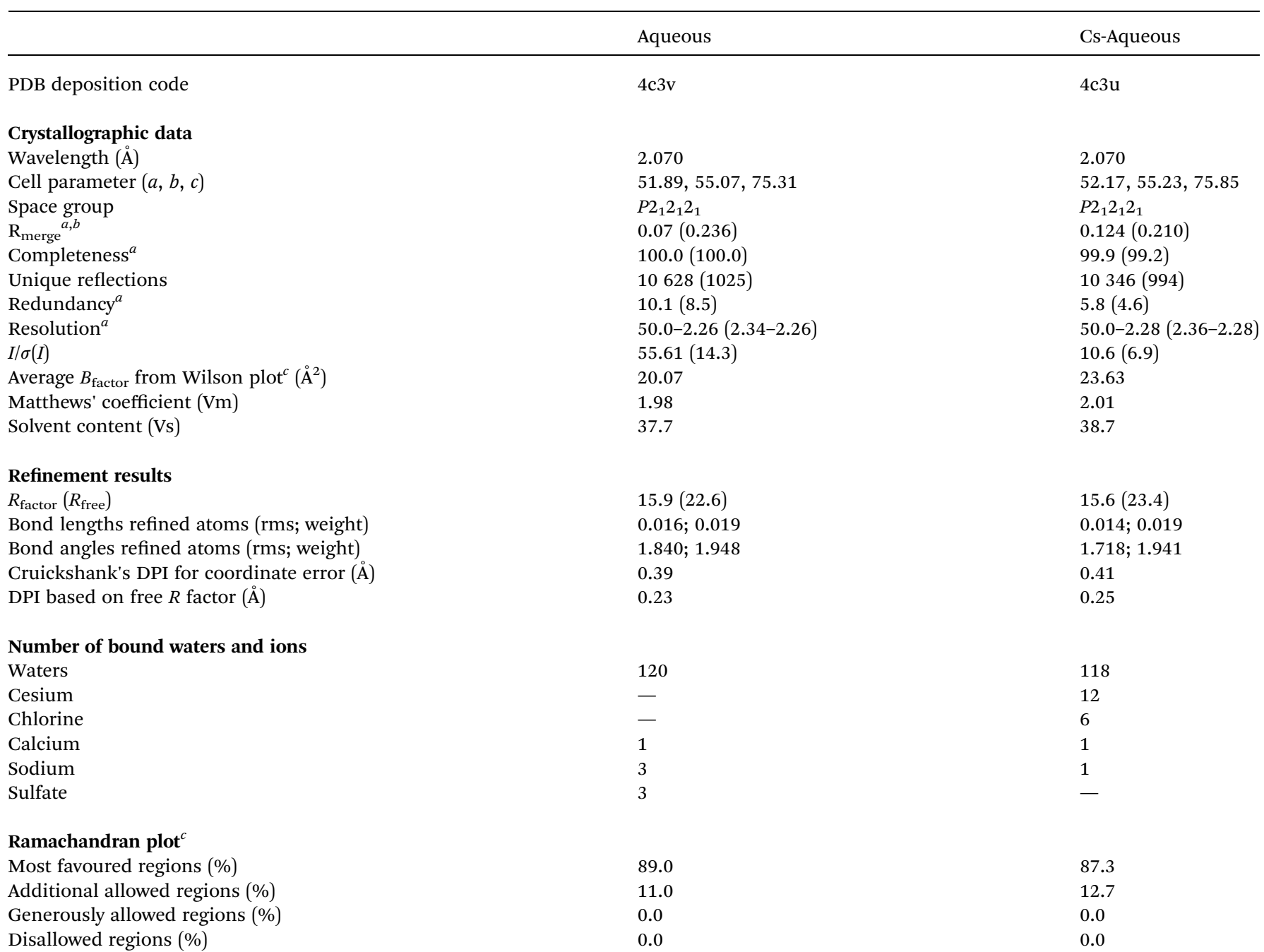

\footnotetext{
${ }^{a}$ The values in parentheses are for the highest-resolution shell. ${ }^{b} R_{\text {merge }}=\Sigma_{h k l} \Sigma_{i}\left|I_{i}(h k l)-\langle I(h k l)\rangle\right| / \Sigma_{h k l} \Sigma_{i}\left|I_{i}(h k l)\right| .{ }^{c}$ Data taken from PROCHECK. ${ }^{25}$
} 


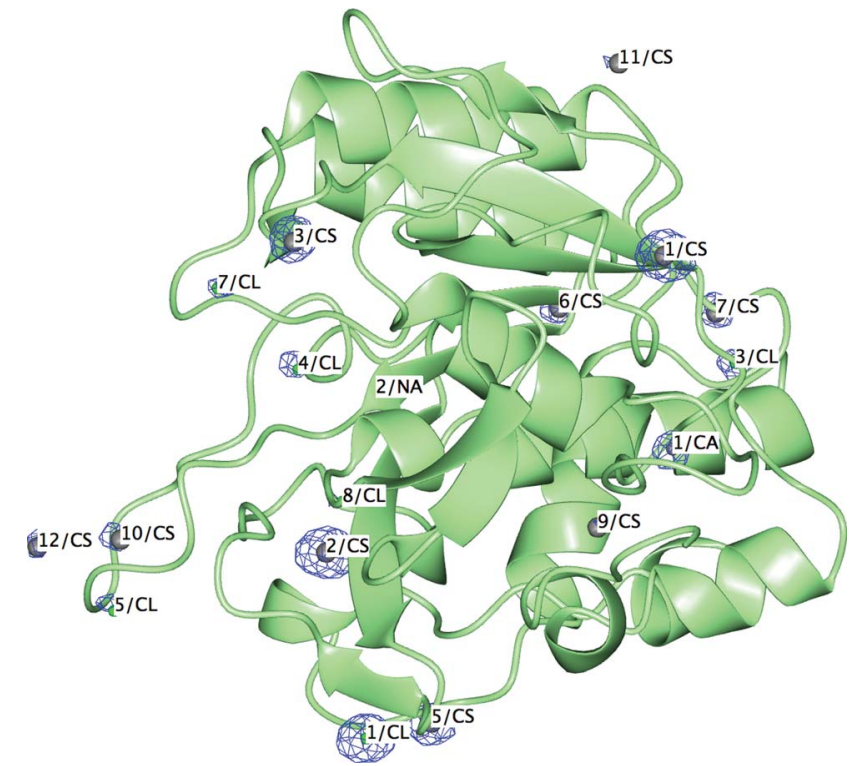

Fig. 1 Crystallographically detected counter-ion sites for subtilisin in water: $\mathrm{Cs}$ in grey, $\mathrm{Cl}$ in green. Anomalous difference electron density Fourier map contour level is at $4 \sigma$. at an X-ray wavelength of $2.070 \AA$ and these data processed using the HKL2000 software package. ${ }^{18}$ Initial crystallographic phases were calculated from the PDB model code $2 \mathrm{WUW}^{\mathbf{1 4}}$ for the aqueous subtilisin model and $2 \mathrm{WUV}^{\mathbf{1 4}}$ for the Cs derivative subtilisin model. These protein molecular models were refined with the CCP4 Refmac $5.0^{19}$ and the protein structure regions displaying different conformations were rebuilt with COOT. ${ }^{20}$ Anomalous difference Fourier electron density maps were calculated and those peaks contoured at a $4 \sigma$ level or higher were considered significant. Ion assignments were made on the basis of coordination geometry at a peak, the map peak height, and finally the $B$-factor and occupancy of each site. The individual $\mathrm{Cl}^{-}$and $\mathrm{Cs}^{+}$ion occupancies were refined with a $B$-factor set equal to the average of their surrounding protein atoms within a radius of $7 \AA$ of each ion. This adjustment was performed using the software program ION_GRINDER, a Python script which uses the Python interfaces of the Computational Crystallography Toolbox (CCTBX) ${ }^{21}$ to work on PDB models. Final $R_{\text {factor }}\left(R_{\text {free }}\right)$ were 15.9 (22.6) and 15.6 (23.4) for the aqueous subtilisin model and for the Cs derivative subtilisin model respectively. Overall X-ray diffraction data and protein model refinement statistics for both are reported in Table 1 . The figures presented in this paper were made using CCP4MG. ${ }^{22}$

Table 2 Ion sites in the aqueous Cs structure. Ion site numbering follows the series reported in Cianci et al. (2010): Occ = ion site occupancy; $B$ $\mathrm{fac}=$ ion $B$-factor; $\sigma$ contour level $=$ maximum peak height of the anomalous difference electron density Fourier map ${ }^{a}$

\begin{tabular}{|c|c|c|c|c|c|}
\hline Atom & Occ. & $B$-fac. & $\sigma$ & Potentially charged groups within $0.8 \mathrm{~nm}$ & Coordinating atoms within $0.4 \mathrm{~nm}$ \\
\hline Cs-1 & 0.73 & 30.31 & 29 & His39 ND (0.68), $\mathrm{Cl}^{* *}(0.76)$ & $\begin{array}{l}\text { Leu42 O (0.30), His39 O (0.30), Ala37 O }(0.30), \text { W40 } \\
(0.34)\end{array}$ \\
\hline Cs-2 & 0.79 & 31.37 & 29 & Cl8 (0.49), Glu195 OE (0.71) & $\begin{array}{l}\text { Ala194 O (0.30), Leu196 O (0.31), Ser260 O (0.31), } \\
\text { Gly193 O (0.33), Ser260 OG (0.39), W34 (0.35), W152 } \\
(0.37)\end{array}$ \\
\hline Cs-3 & 0.26 & 31.86 & 11 & $\mathrm{Cl} 7$ (0.72), Asp60 OD (0.79) & Ser98 O (0.33), Gly61 O (0.33), W98 (0.25) \\
\hline Cs-5 & 0.36 & 33.76 & 11 & Glu54** OE $(0.39)$ & $\begin{array}{l}\text { Tyr256 ring C's }(0.34-0.39), \mathrm{W} 127^{* *}(0.31), \mathrm{Glu} 54^{* *} \\
\text { OE }(0.39), \text { Ala } 52^{* *} \mathrm{O}(0.29)\end{array}$ \\
\hline Cs-6 & 0.24 & 31.37 & 6 & $\operatorname{Arg} 247 \mathrm{NH}(0.72)$ & $\begin{array}{l}\text { Tyr143 O (0.33), Ser244 OG (0.37), Tyr143 ring C's } \\
(0.37-0.39), \text { W113 }(0.23)\end{array}$ \\
\hline Cs-7 & 0.24 & 35.68 & 7 & Asp120 OD (0.57), Cl3 (0.71) & $\begin{array}{l}\text { Leu241 O (0.28), Pro239 O (0.32), W46 (0.27), W62 } \\
(0.28), \text { W119 (0.32) }\end{array}$ \\
\hline Cs-9 & 0.22 & 29.49 & 4 & Ala1 N (0.50), Asp41 OD (0.77) & $\begin{array}{l}\text { Thr3 OG (0.28), Ala1 O (0.30), Gly80 O (0.33), Thr3 N } \\
(0.38) \text {, W53 (0.27), W107**(0.23) }\end{array}$ \\
\hline Cs-10 & 0.12 & 34.61 & 5 & Cl5 (0.42), Arg186 NH (0.71) & Ser156 O (0.33), Asn158 O (0.34) \\
\hline Cs-11 & 0.12 & 29.94 & 4 & None & Gly47 O (0.35), Tyr57 OH (0.40) \\
\hline Cs-12 & 0.24 & 45.47 & 5 & None & Ser159 O (0.31), Thr162 OG (0.31), Ser159 OG (0.37) \\
\hline $\mathrm{Cl}-1$ & 1.00 & 16.00 & 22 & Asp181 OD (0.76) & $\begin{array}{l}\text { Asn185 ND (0.30), Ser184 O }(0.33), \text { Tyr263 OH }(0.38) \text {, } \\
\text { Leu257 O (0.38), W123 (0.34), Gln2** O }(0.28), \\
\text { W54** }(0.36)\end{array}$ \\
\hline $\mathrm{Cl}-3$ & 0.74 & 39.36 & 6 & $\operatorname{Cs} 7(0.71), \operatorname{Cs} 1 * *(0.76)$ & Asn240 O (0.30), Gln245 NE (0.32) \\
\hline Cl-4 & 0.64 & 31.88 & 5 & $\begin{array}{l}\text { Glu195 OE (0.41), Asp172 OD (0.51), Na2 } \\
(0.63), \text { Lys170 NZ }\left(0.67^{*}\right), \text { Lys136 NZ } \\
\left(0.73^{*}\right), \text { Tyr167 OH }(0.61)\end{array}$ & Lys170 O (0.30), W3 (0.35), W87 (0.40) \\
\hline $\mathrm{Cl}-5$ & 0.48 & 44.62 & 5 & $\begin{array}{l}\text { Lys15** NZ (0.38), Cs10 (0.42), Arg186 } \\
\text { NH }(0.66)\end{array}$ & Asn158 O (0.29), Asn158 ND (0.29) \\
\hline $\mathrm{Cl}-7$ & 0.39 & 32.75 & 5 & Lys265** NZ (0.69), Cs3 (0.72) & Ser99 O (0.30), W147 (0.33), Asn248** ND (0.31) \\
\hline Cl-8 & 0.27 & 25.81 & 4 & $\begin{array}{l}\text { Cs2 (0.49), Glu195 OE (0.66), Glu197 OE } \\
(0.76)\end{array}$ & Ala194 O (0.30), W22 (0.32) \\
\hline
\end{tabular}

${ }^{a}$ Atoms are identified by the usual PDB codes, with O, being the alpha-carbonyl oxygen; * - the amino groups of Lys136 and Lys170 appear to be in salt bridges with the carboxylates of Asp140 and Glu195 respectively; ** - these groups are in an adjacent protein molecule in the crystal. 


\section{Results and discussion}

The clear anomalous signal shows very well defined sites $(>4 \sigma$ level Fig. 1 and Table 2). All the caesium sites, and most of the chloride ones, had partial occupancies. The total occupancies for $\mathrm{Cs}^{+}$and $\mathrm{Cl}^{-}$sum to +3.3 and -3.5 respectively, indicating almost zero $(-0.2)$ net charge from the counter-ions. In contrast, the caesium and chloride counter-ions in the previously determined subtilisin crystal structure in acetonitrile had a net charge of -1.7 .

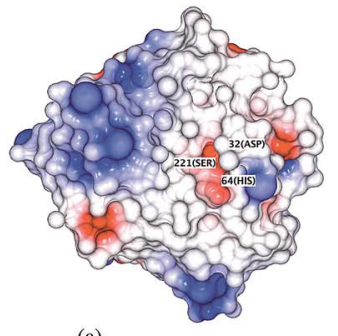

(a)

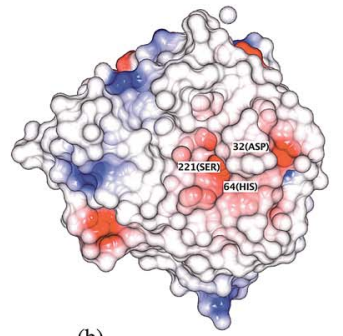

(b)

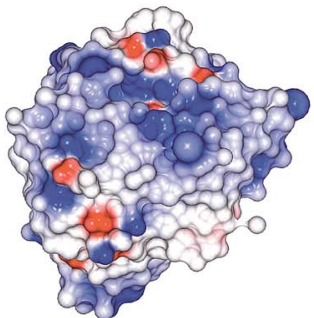

(c)

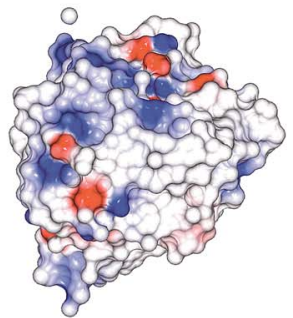

(d)

Fig. 2 Change of electrostatic potential of the protein surface. Red areas have a negative potential, blue areas a positive potential, white areas are neutral. (a) Subtilisin soaked in a $\mathrm{CsCl}$ salt aqueous solution; (b) in aqueous solution; (c and d) views at $180^{\circ}$. Electrostatic potential of the protein surface were computed using CCP4MG. ${ }^{22}$
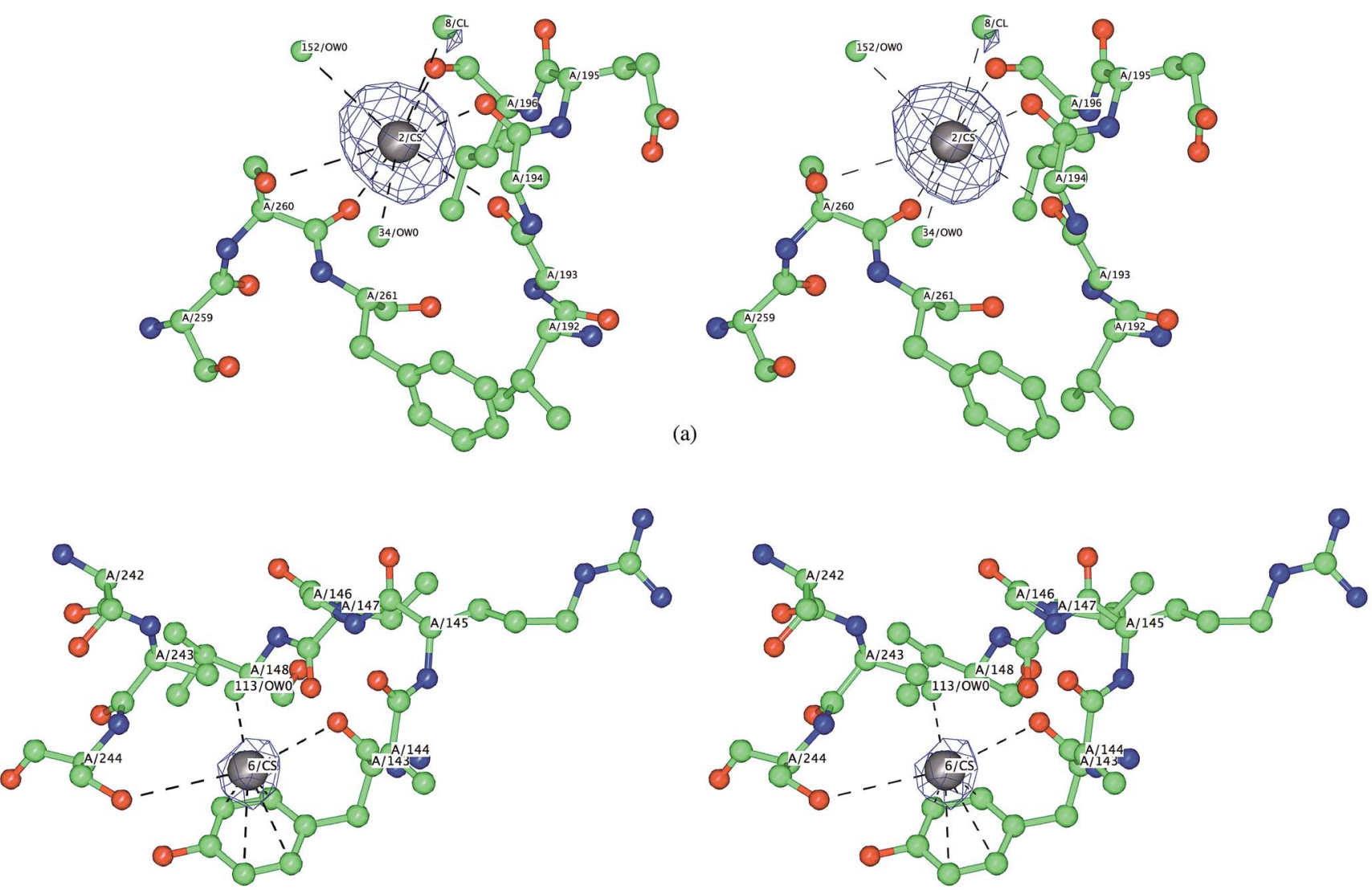

(b)

Fig. 3 Stereo view of two representative $\mathrm{Cs}^{+}$ion binding sites. Atoms colored according to atom type: blue $=\mathrm{N}$; red $=\mathrm{O} ;$ green $=\mathrm{C}$, grey $=\mathrm{Cs}$. Anomalous difference Fourier map contour level at $4 \sigma$. (a) Cs site 2 coordination by carbonyls; (b) Cs site 6 interacting with tyrosine ring. 
in area on the protein surface overall and in close proximity of the catalytic triad (Fig. 2). Molecular dynamics simulations show a poor agreement of the distribution of chloride ions on the subtilisin surface in an aqueous medium compared with the anion sites observed crystallographically. ${ }^{23}$ It was calculated that the surface potential of subtilisin is more negative in aqueous solution than in the crystal, limiting the binding of anions. ${ }^{23}$ In fact, patches of negative electric potential do not show an extension of the areas in a high salt condition (Fig. 2).

Protein electrical potential surfaces are commonly calculated and discussed in structure-function relationships. However, such calculations normally do not consider any counter-ions, as well as the intrinsic difficulty of predicting ionisable amino acid side chain pKas, ${ }^{24}$ and electric potentials are very different and even opposite in sign if counter-ions are included. ${ }^{\mathbf{1 4 2 3}}$ Clearly, an experimental determination of the cation and anion substructures should be sought for any of those systems where electrical potential surfaces are studied, especially at high salt concentrations.

Previous suggestions are that cations are expected to be coordinated mainly by hydrated protein side-chain carboxylates, with a minor contribution from carbonyl oxygens and other side chains. ${ }^{\mathbf{8}, 10}$ In contrast, we observe that, most of the $\mathrm{Cs}^{+}$ions are predominantly coordinated by formally neutral oxygens, mostly backbone carbonyls: Fig. 3a shows Cs site 2 as an example. Two of the $\mathrm{Cs}^{+}$ions appear to show coordination by the aromatic rings of Tyr residues, presumably in a charge $-\pi$ interaction (Fig. 3b). Only Cs site 5 is closely associated with a charged protein group, and since it interacts with two different protein molecules, the site is probably an artefact of the crystal packing. The "law of matching water affinity" would suggest relatively weak association of large cations like $\mathrm{Cs}^{+}$with protein carboxylates.

Most of the $\mathrm{Cl}^{-}$ion sites have relatively few of the potential $\mathrm{H}$-bond donors and they are also not near likely protein +ve charges. All the sites show coordinating interactions with an atom in an adjacent protein molecule in the crystal. $\mathrm{Cl}$ site 5 , for instance, is placed between a Lys amino group and $\mathrm{a} \mathrm{Cs}^{+}$ion associated with the symmetry related molecule and it might be a crystal packing site. In these cases we have to accept the possibility that Cl-sites are a result of crystal packing, as confirmed by the results of the molecular dynamics simulations, ${ }^{23}$ and would not have particular affinity for counter-ions when the enzyme is in solution. This possibility is also in agreement with the observation that $\mathrm{Cl}^{-}$binds far more weakly to the protein surface. ${ }^{\mathbf{1 1}}$

We can also compare the counter-ion sites found in this study with those in previously reported studies, and also with one for our aqueous crystals not soaked with $\mathrm{CsCl}$ (Table 2). The tightly bound $\mathrm{Ca}-1$ is conserved across all reported subtilisin structures.

In the Cs- 1 site, three of the previously determined crystal structures reported a $\mathrm{Ca}^{2+}$ (Table 3 ). In our aqueous structure that has not had a $\mathrm{CsCl}$ soak, we confirm a sodium atom (Na-1)

Table 3 Equivalent ion sites in related PDB structures of subtilisin Carlsberg

\begin{tabular}{|c|c|c|c|c|c|c|c|c|c|c|c|c|}
\hline $\begin{array}{l}\text { Cs ion } \\
\text { structure }\end{array}$ & $\begin{array}{l}\text { Native } \\
\text { structure }\end{array}$ & $1 \mathrm{CSE}$ & 1C3L & 1SCA & $1 \mathrm{SCN}$ & 2SEC & 2WUV & 2WUW & 1SCB & 1SCD & $1 \mathrm{AF} 4$ & $1 \mathrm{BFU}$ \\
\hline Water & Water & Water & Water & Water & Water & Water & Acetonitrile & Acetonitrile & Acetonitrile & Acetonitrile & $\begin{array}{l}\text { Dioxane } \\
100 \%\end{array}$ & $\begin{array}{l}\text { Dioxane } \\
20 \%\end{array}$ \\
\hline Cs-1 & $\mathrm{Na}-1$ & - & - & $\mathrm{Ca}-403$ & $\mathrm{Ca}-403$ & $\mathrm{Ca}-278$ & Cs-1 & $\mathrm{Na}-1277$ & W371 & W598 & - & W315 \\
\hline Cs-2 & $\mathrm{Na}-3$ & W57 & W398 & W578 & W582 & W382 & Cs-2 & W2114 & W357 & W539 & - & - \\
\hline Cs-3 & - & W795 & - & W681 & - & - & Cs-3 & - & - & - & - & - \\
\hline- & - & - & - & - & - & - & Cs-4 & - & - & W597 & - & - \\
\hline Cs-5 & - & - & - & W577 & - & - & Cs-5 & - & - & - & - & - \\
\hline Cs-6 & - & - & W389 & - & - & W433 & Cs-6 & - & W113 & - & - & - \\
\hline Cs-7 & - & W602 & - & - & - & - & Cs-7 & - & W398 & - & - & - \\
\hline- & - & W519 & - & - & - & - & Cs-8 & - & - & W511 & - & - \\
\hline Cs-9 & W12 & W427 & W351 & W627 & - & W422 & Cs-9 & W2039 & - & W629 & W322 & W336 \\
\hline Cs-10 & - & W698 & - & - & - & - & Cs-10 & - & - & - & - & - \\
\hline Cs-11 & W125 & - & - & - & - & - & Cs-11 & - & - & - & - & - \\
\hline Cs-12 & - & - & - & - & - & - & - & - & - & - & - & - \\
\hline $\mathrm{Ca}-1$ & $\mathrm{Ca}-1$ & $\mathrm{Ca}-1$ & $\mathrm{Ca}-1$ & $\mathrm{Ca}-1$ & $\mathrm{Ca}-1$ & $\mathrm{Ca}-1$ & $\mathrm{Ca}-1$ & $\mathrm{Ca}-1279$ & $\mathrm{Ca}-1$ & $\mathrm{Ca}-1$ & $\mathrm{Ca}-1$ & $\mathrm{Ca}-1$ \\
\hline $\mathrm{Na}-2$ & $\mathrm{Na}-2$ & $\mathrm{Ca}-401$ & Ca-284 & Na-402 & - & $\mathrm{Ca}-277$ & $\mathrm{Na}-2$ & $\mathrm{Na}-1278$ & W359 & $\mathrm{Ca}-403$ & W305 & W294 \\
\hline Cl-1 & W18 & W885 & - & - & - & W489 & Cl-1 & - & - & W582 & W299 & - \\
\hline- & W97 & W503 & W404 & W662 & W665 & W484 & $\mathrm{Cl}-2$ & - & W285 & W518 & W326 & - \\
\hline $\mathrm{Cl}-3$ & - & W577 & - & - & - & - & $\mathrm{Cl}-3$ & - & - & - & - & - \\
\hline Cl-4 & - & - & - & - & - & - & Cl-4 & - & - & - & - & - \\
\hline Cl-5 & - & - & - & - & - & - & Cl-5 & - & - & - & - & - \\
\hline- & SO4 & - & W334 & - & W590 & - & Cl-6 & SO4 & - & - & - & W304 \\
\hline Cl-7 & - & W492 & - & - & - & - & $\mathrm{Cl}-7$ & - & W384 & - & - & - \\
\hline Cl-8 & - & - & - & - & W640 & W463 & Cl-8 & - & W372 & - & - & - \\
\hline
\end{tabular}


in this position distinguishing it from a water or from bivalent cation site. In site Cs-2, a water molecule is modelled in all five previous structures. Four carbonyl oxygens, a side chain hydroxyl and a water molecule coordinate the site. This appears more like octahedral coordination rather than a tetrahedron of waters. For all but one of the other $\mathrm{Cs}^{+}$sites in our structure, a water molecule has been modelled in at least one of the other aqueous structures. In many of these sites the coordination geometry does not obviously indicate a counter-ion rather than a water molecule, so without the optimized anomalous difference electron density data it would not be easily recognized. Our structure also contains a site clearly assigned to a $\mathrm{Na}^{+}(\mathrm{Na}-2)$. The same site has been reported as containing $\mathrm{Na}^{+}$in some other structures, but as a second $\mathrm{Ca}^{2+}$ in others (Table 3). This site showed no anomalous difference Fourier map peak at 2.070 $\AA$ wavelength, which excluded a $\mathrm{Ca}^{2+}\left(\mathrm{Ca}^{2+} \mathrm{f}\right.$ " at this wavelength is $2.95 \mathrm{e}^{-}$). The assignment as a calcium is not supported by our findings.

Turning to the $\mathrm{Cl}^{-}$sites we identify, four of the six sites have been modelled as containing waters in one or more of the previously reported crystal structures.

We can also compare the counter-ion sites with those found in our previous subtilisin crystal structure soaked with $\mathrm{CsCl}$ and acetonitrile (2WUV). ${ }^{14}$ All but one $\mathrm{Cs}^{+}$site, and all the $\mathrm{Cl}^{-}$sites, were also found in this acetonitrile structure (Table 2). In addition, the acetonitrile based crystal structure had further counter-ion sites, $2 \mathrm{Cs}^{+}$and $2 \mathrm{Cl}^{-}$, which are not found in the aqueous crystal structure. The favoured sites for ion interactions are not very different in acetonitrile and aqueous media in subtilisin.

\section{Conclusions}

The present study extends the understanding association of counter-ions with the surface of subtilisin and of proteins in general. Subtilisin shows significant numbers of defined counter-ion sites even in aqueous conditions i.e. with its large dielectric constant. Most counter-ion sites did not involve close interaction with formal protein charges. The presence of these counter-ions substantially changes the protein electrical potential surface, and which is an effect commonly discussed in relation to function.

The interactions between proteins and counter-ions may have important influences on enzyme function, especially in systems where quite high salt concentrations are encountered. To understand these effects, it is important to have information about the sites of interaction, and which we provide in this case study.

\section{Acknowledgements}

We are grateful to STFC Daresbury Laboratory for the provision of beamtime. Dr D. Lousa and Prof. C. M. Soares (Universida de Nova de Lisboa) are thanked for the helpful discussions. Structures with and without Cs have been deposited to Protein Data Bank codes: $4 \mathrm{c} 3 \mathrm{u}$ and $4 \mathrm{c} 3 \mathrm{v}$.

\section{References}

1 R. L. Baldwin, Biophys. J., 1996, 71, 2056-2063.

2 D. J. Tobias and J. C. Hemminger, Science, 2008, 319, 11971198.

3 T. Dudev and C. Lim, Chem. Rev., 2014, 114, 538-556.

4 P. Jungwirth and B. Winter, Annu. Rev. Phys. Chem., 2008, 59, 343-366.

5 W. Kunz, Curr. Opin. Colloid Interface Sci., 2010, 15, 34-39.

6 P. Lo Nostro and B. W. Ninham, Chem. Rev., 2012, 112, 22862322.

7 Y. Zhang and P. S. Cremer, Curr. Opin. Chem. Biol., 2006, 10, 658-663.

8 L. Vrbka, J. Vondrášek, B. Jagoda-Cwiklik, R. Vácha and P. Jungwirth, Proc. Natl. Acad. Sci. U. S. A., 2006, 103, 15440-15444.

9 K. D. Collins, Biophys. Chem., 2012, 167, 43-59.

10 K. D. Collins, Biophys. Chem., 2006, 119, 271-281.

11 K. B. Rembert, J. Paterová, J. Heyda, C. Hilty, P. Jungwirth and P. S. Cremer, J. Am. Chem. Soc., 2012, 134, 10039-10046.

12 M. Cianci, P. J. Rizkallah, A. Olczak, J. Raftery, N. E. Chayen, P. F. Zagalsky and J. R. Helliwell, Acta Crystallogr., Sect. D: Biol. Crystallogr., 2001, 57, 1219-1229.

13 K. Djinovic-Carugo, J. R. Helliwell, H. Stuhrmann and M. S. Weiss, J. Synchrotron Radiat., 2005, 12, 410-419.

14 M. Cianci, B. Tomaszewski, J. R. Helliwell and P. J. Halling, J. Am. Chem. Soc., 2010, 132, 2293-2300.

15 C. Mueller-Dieckmann, S. Panjikar, A. Schmidt, S. Mueller, J. Kuper, A. Geerlof, M. Wilmanns, R. K. Singh, P. A. Tucker and M. S. Weiss, Acta Crystallogr., Sect. D: Biol. Crystallogr., 2007, 63, 366-380.

16 D. N. Okamoto, M. Y. Kondo, J. A. N. Santos, S. Nakajima, K. Hiraga, K. Oda, M. A. Juliano, L. Juliano and I. E. Gouvea, Biochim. Biophys. Acta, 2009, 1794, 367-373.

17 M. Cianci, S. Antonyuk, N. Bliss, M. W. Bailey, S. G. Buffey, K. C. Cheung, J. A. Clarke, G. E. Derbyshire, M. J. Ellis, M. J. Enderby, A. F. Grant, M. P. Holbourn, D. Laundy, C. Nave, R. Ryder, P. Stephenson, J. R. Helliwell and S. S. Hasnain, J. Synchrotron Radiat., 2005, 12, 455-466.

18 Z. Otwinowski and W. Minor, Methods Enzymol., 1997, 276, 307-326.

19 G. N. Murshudov, A. A. Vagin and E. J. Dodson, Acta Crystallogr., Sect. D: Biol. Crystallogr., 1996, 53, 240-255.

20 P. Emsley, B. Lohkamp, W. G. Scott and K. Cowtan, Acta Crystallogr., Sect. D: Biol. Crystallogr., 2010, 66, 486-501.

21 R. W. Grosse-Kunstleve, N. K. Sauter, N. W. Moriarty and P. D. Adams, J. Appl. Crystallogr., 2002, 35, 126-136.

22 S. McNicholas, E. Potterton, K. S. Wilson and M. E. M. Noble, Acta Crystallogr., Sect. D: Biol. Crystallogr., 2011, 67, 386-394.

23 D. Lousa, M. Cianci, J. R. Helliwell, P. J. Halling, A. M. Baptista and C. M. Soares, J. Phys. Chem. B, 2012, 116, 5838-5848.

24 S. J. Fisher, J. Wilkinson, R. H. Henchman and J. R. Helliwell, Crystallogr. Rev., 2009, 15, 231-259.

25 R. A. Laskowski, M. W. MacArthur, D. S. Moss and J. M. Thornton, J. Appl. Crystallogr., 1993, 26, 283-291. 